\title{
Paradigm Shift of New Building in Old Urban Districts: Case Study of Bangkok Chinatown Workshop*
}

\author{
Xian $\mathrm{Li}^{1}{ }^{\mathrm{a} \dagger}$, Eakachat Joneurairatana ${ }^{2 \mathrm{~b}}$, Veerawat Sirivesmas ${ }^{3 \mathrm{c}}$ \\ ${ }^{1}$ Faculty of Decorative Arts Silpakorn University, Bangkok Thailand \\ ${ }^{2}$ Faculty of Decorative Arts Silpakorn University, Bangkok Thailand \\ ${ }^{3}$ Faculty of Decorative Arts Silpakorn University, Bangkok Thailand
}

\begin{abstract}
Architects and designers realize that new buildings cannot completely replace old buildings in the process of urbanization in the world. To establish a method of the new building and the old building coexist and to create the new paradigm of the new building construction in the old district is the responsibility faced by the contemporary architects. This paper first analyzes the old building renovation projects in Berlin and Paris in the 1980s and puts forward the symbiotic relationship between the old and the new buildings in the new era, thus obtaining the research objectives, trying to redefine new buildings and old districts, and creating the new paradigm of contemporary building construction in old districts. Using workshop as an exploration method, this paper conducts data research and sampling analyses on the Chinatown area in Bangkok, and explores the combination mode and paradigm transformation of new buildings and old districts in the city, aiming to seek solutions utilizing art exploration.
\end{abstract}

\section{Introduction}

The city is a contradictory complex [13]. On the one hand, the city tries to keep the traditional and regional characteristics that make it different from other cities. On the other hand, under the influence of globalization style, the city has to evolve towards the same style homogeneity [1]. To maintain the equilibrium relationship between the old and the new in urban architecture, while maintaining its architectural style and characteristics, has always been the responsibility faced by architects and urban planners [6].

This case takes Thailand's Chinatown area as the exploration and research object, trying to explore the general laws and possibilities of urban development through art workshops, focusing on the core issues of public concern through art, resolving the contradictions between the old and new buildings in urban planning through sensibility, and exploring a possibility of construction in future.

\subsection{Literature and case study}

Urban regeneration is objective research, and building from new to old is also a normal process of urban metabolism [14]. Old buildings cannot meet the needs of modern cities in the process of rapid urban expansion, and because of the capital and technical conditions that cannot be achieved. Old and new buildings coexisting in urban districts, and they will co-exist for a long time [11]. More and more architects focus on the low-cost renewal and micro transformation projects of old urban districts [4]. But what are the old buildings of the city, what are the new buildings needed by the city, and what are their existing laws and development possibilities in the process of the new buildings becoming old and the trend of the new buildings imitating the antique.

Since the 1920s, with technological innovation and the use of new materials, the development of modernism architecture has changed the face of global cities. The new architecture defined here is mainly modern style architecture, and also covers the architectural form after modernism. Urban renewal is mainly this kind of new building, how to integrate into the existing urban districts reasonably. From the urban renewal projects of many big cities in history, we can also see some methods of urban renewal and the integration process of new and old buildings.

The International Building Exhibition Berlin (IBA Berlin) was an urban renewal project in West Berlin, Germany. Initiated in 1979, it was completed in 1987, matching the 750th anniversary of the founding of Berlin [15]. The IBA followed two distinct strategies: "careful urban renewal" and "critical reconstruction" $[2,8]$. The organizers of IBA advocate that the new buildings should be integrated into the existing cities, rather than the early new buildings should be independent in the Suburban Park, and the combination of new buildings and old buildings should be used to deal with the urban texture and social problems of Berlin [16]. Under the guidance of IBA, the new building should be consistent with the regional tradition and history and continue. In the aspect of old

\footnotetext{
ali_x@silpakorn.edu

bmdltgd@yeah.net

veerawatsi@gmail.com
} 
building restoration and renewal, the applicability of materials is simplified and residents are allowed to participate, and the experimental building is designed in Wohnregal, Berlin [7,9].

The Grands Projects of François Mitterrand was an architectural program to provide modern monuments in Paris, the city of monuments, symbolizing France's role in art, politics, and economy at the end of the 20th century $[5,17]$. From the urban intervention projects in Spain and France, we can see the methods of integrating new architectural language: first, dramatic new architectural language, decoration of old buildings. Second, insert a very new element without changing the surrounding environment. Third, the use of a unified architectural language, regardless of other factors [7]. (Figure 1)
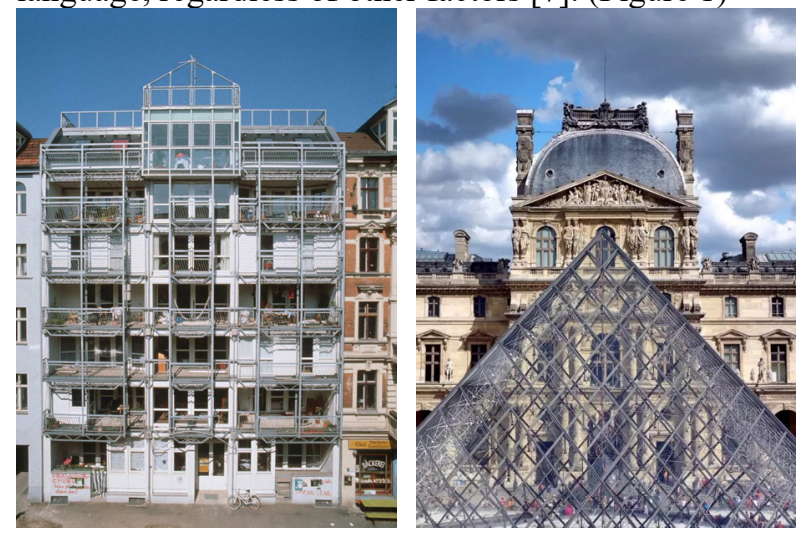

Figure 1: Wohnregal in Berlin (left) and Louvre Pyramid in Paris (right)

\subsection{Question ad Objectives}

To sum up, to integrate the new urban buildings into the old buildings has always been the problem of urban architects. This paper discusses the symbiotic relationship between new buildings and old buildings, as well as the development direction of new buildings in the future. First of all, the problem of this paper is clear: the contradiction between the new building and the old original environment cannot be integrated into the process of urbanization. Through literature and case studies, found that the research on the relationship between new buildings and old districts is mutual integration. Therefore, the main question of this paper is: how to achieve the integration of new buildings in old urban districts and change the existing mode into a new paradigm. To return to this question, first of all, what is the concept of new and old in contemporary urban districts? Secondly, what is the junction of the old and new buildings in the city district? Two objectives of the paper are obtained from the questions:

1. To redefine the old and new buildings in the old districts; and

2. To create a new paradigm between the old and the new buildings in the old districts.

To define the concept of new and old in the new definition district, taking Thailand's Chinatown as the research object, the concept and element list system of new buildings and old buildings in the contemporary urban district are obtained after data investigation and analyses. Based on this, the junction between new and old buildings is found as the basis. To evaluate the junction between the old and the new buildings, the targeted data collection is conducted again on Bangkok Chinatown. The old and new buildings that can represent the characteristics of the district are selected for two rounds of screening. Finally, the core data is obtained. The new and old buildings with the most core data are the new paradigm of the old and new buildings in the development of urban districts. (Figure 2)

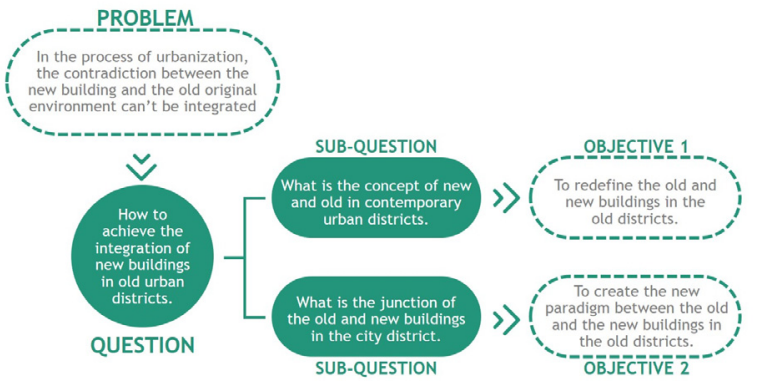

Figure 2: Research Framework

\section{Materials and methods}

As a method and effective way to explore complex problems in a short period, workshops can gather people from different regions and different professional backgrounds to stimulate new ideas [3]. In exploring the relationship between new buildings and old buildings, it is a complex social problem, which cannot be solved by a single architectural design method. The purpose of the workshop is to find out the development trend of the new buildings in the old districts of the city from the new definition of the old and new buildings in the city through the method of data research and quantitative analyses.

The workshop is composed of students from Silpakorn University and Tokyo University of Art, including 1 Thai, 1 Chinese, and 2 Japanese. The main districts of the group are Yaowarat Road and Charoen Krung Road of Chinatown in Bangkok. (Figure 3)

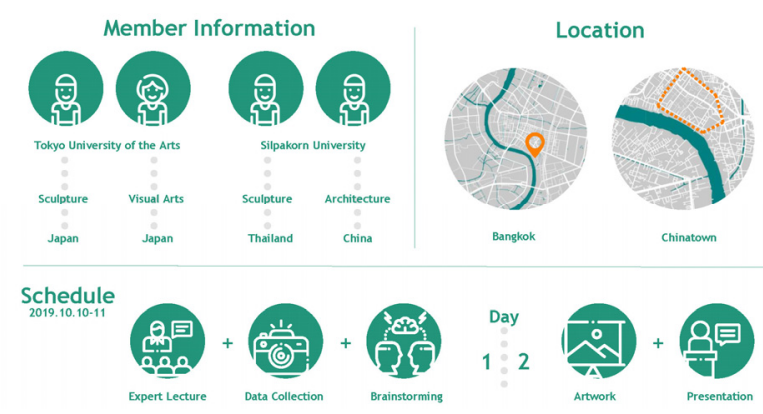

Figure 3: Information on Workshop

In this area, they collect local architectural photos, traditional artifacts, and local symbols and patterns. Analyses of the pictures and screening, and finally college art creation, to explore the possibility of the development of the old street, and to explore the process of thinking and conclusion to complete the summary. Collage art, as a common form of expression and technical means of popular art, can combine the transformation of the twodimensional interface and three-dimensional space, making the work more expressive [10]. Here, it is used as 
the artistic expression method of the combination of new buildings and old buildings. It is in line with the conditions for members of different backgrounds to participate in the workshop. It is also a common method in design teaching and workshop activities [12].

In the process of data collection with Thailand Chinatown as the sample object, the photo data went through two sample screening processes. For the first time, members of the workshop team need to use the redefinition of the old and new buildings as the data collection principle to shoot representative buildings and scenes in the district. In the second time, the team members obtained the final core data by re-screening the photo data of other people. In the limited conditions of this small-scale and short-term workshop project, this is the core element that can best represent the characteristics of this district. Finally, the number of photo data of core elements is summarized in the definition of new and old buildings. From the proportion of data, the relationship between the old and the new buildings is observed and analyzed, and the paradigm transformation of new buildings in the old districts is deduced.

\section{Process of analyses}

\subsection{Site analyses}

The change in new buildings in the city is an irreversible fact. If we balance the relationship between new buildings and old districts, it is the key point for the city to explore its development direction. For Thailand's Chinatown area, Yaowarat Road and Charoen Krung Road used to be the commercial center of Bangkok, with a history of 200 years, but with the development of new business and CBD migration, Chinatown gradually blight. The whole Chinatown area is about two kilometers long, which is connected by Sampang Lane, Yaowarat Road, Charoen Krung Road, and other streets. Due to the changes of the times, this area now integrates a Chinese gathering area, Indian gathering area, Muslim gathering area, etc. the cultural integration makes the buildings in this district also diverse and inclusive. Most of the buildings in this area are old, but the business is very prosperous. Although most of the buildings are mainly built in the Chaoshan area of China, we can also see the integration and change of various cultures. (Figure 4)

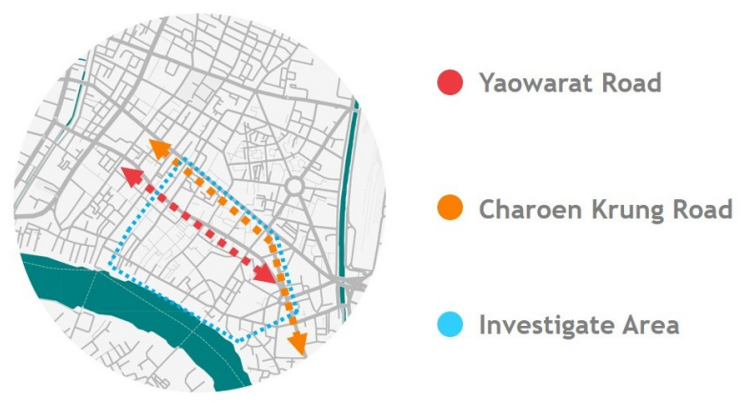

Figure 4: Investigate Area in Chinatown of Bangkok

\subsection{Defining the old in urban architecture}

To clarify the relationship between the old and the new buildings in the city, it is necessary to make a new definition of new buildings and old buildings. This definition is based on the existing buildings in Bangkok's Chinatown area based on practical research. (Figure 5)

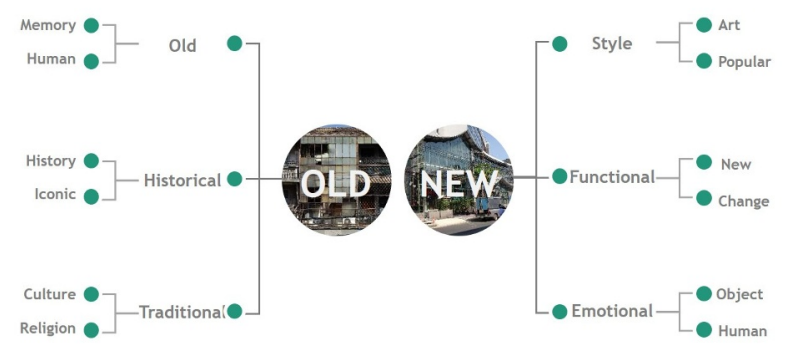

Figure 5: Categories of the Old and New

\subsubsection{Old buildings}

Old buildings are the main part of urban buildings, and they will also be recorded in the subsequent data analyses. The old buildings cover two meanings, one is memory, the other is humanization. Objects all use the process from new to old, and the memory produced in this process is the unique charm of old urban buildings. This kind of old has nothing to do with traditional history but only occurs in the connection between the residents and the building itself. Humanization also has such characteristics. Under the urgent needs of users, the old buildings have been adjusted to reflect the low-cost humanistic care. This is not the designer's talk on paper, but also the external embodiment of life traces.

\subsubsection{Historic buildings}

The architecture of the city represents the history of the city, which is also the core value of Bangkok different from other places. There are two kinds of historicity: one is the building with historical value, which is generally the old building or the repaired old building. It is the witness of a certain period of history and the nostalgic object. The other is a landmark building, or call it a sign. This sign represents the symbol and image of the city. It may be the reconstruction after the disappearance of the historical building and the spiritual sustenance of the city.

\subsubsection{Traditional architecture}

Traditional architecture includes cultural tradition and religious tradition. Cultural tradition is the foundation of maintaining a close type of regional community. For example, there are Chinese areas in Bangkok's Chinatown area, and traditional markets and Chinese schools are the gathering places for maintaining the traditional community. The religious tradition is better understood. A large number of temples, Hindu temples, and mosques are carriers of the unique culture of Bangkok's Chinatown, gathering various ethnic groups in the process of mutual integration and maintaining their unique places. 


\subsection{New buildings in the city}

\subsubsection{New buildings in style}

The new architecture in architectural style includes the trend of popularity and the expression of contemporary art. From the beginning of modern architecture, square box architecture has become the main body of the world's architectural development, even the post-modern architecture is also based on modern architecture to add additions to make the architecture more meaningful. Therefore, the way of building this new building is a trend and an unavoidable topic. Besides, more and more art elements are added to the surface of the building. Sometimes the boundary between art and the trend left behind may be blurred, which means that the artistic surface form is also the popular trend of the building.

\subsubsection{New buildings in function}

The development of human society makes the social division of labor more detailed and the resulting new community functions evolve into buildings with new functional forms. For example, there was no super large shopping mall in the previous society, which is the building under the new functions. However, under this new functional phase, the buildings will gradually replace the obsolete building functions. Maybe the traditional market has been transformed into a supermarket, so the new functions cover the new functional buildings and the buildings that change the use functions.

\subsubsection{New buildings in emotion}

Emotional new building is to build a new building at the same time hope to retain the traditional emotional sustenance, it does not contain a historical value, just add emotional symbols to the new building. There are two meanings to this symbol. One is that it is based on objects, such as adding a traditional attic to modern architecture, which is out of place and grotesque. Second, buildings without human feelings are often lifeless, so they will be endowed with human feelings through graffiti and other ways.

\subsection{Data collection}

Based on the analyses of the old and new characteristics of the city, 12 kinds of elements are summed up and targeted to explore the Thai Chinatown area and collect relevant pictures and materials. Based on this data, collage art is created by the following principles: (Figure 6)

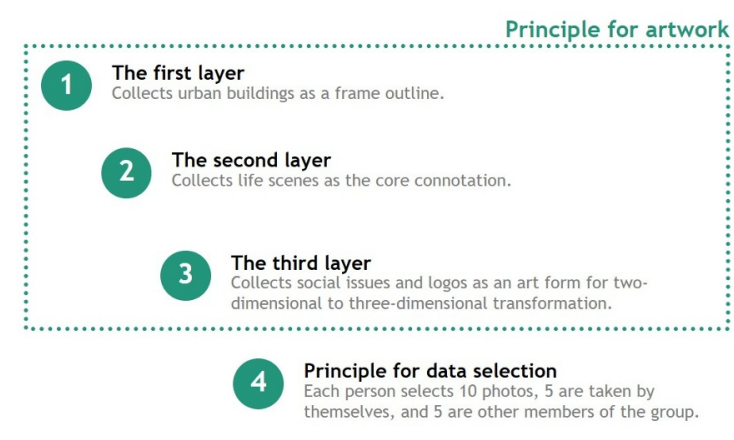

Figure 6: Principles of Workshop Picture Collection

1. Collect the shape of urban buildings as the outline of artistic creation;

2. Collect the living details of residents as the connection node between the city and people;

3. Collect social phenomena and physical symbols as a way to transform two-dimensional art into threedimensional art; and

4. In data selection, select 5 photos taken by yourself and 5 photos not taken by yourself as creation materials.

\subsection{Data analyses and conclusion}

Through quantitative analyses of the pictures selected from a small range, found that in the selection of old building elements, the number of pictures defined as old buildings is large, accounting for $70 \%$; the number of pictures of historical buildings is $30 \%$; the number of pictures of traditional buildings is $50 \%$. (Figure 7) In the selection of new architectural elements, the number of pictures defined as the new style is $50 \%$; the number of pictures defined as the new function is $30 \%$; the number of new architectural pictures in emotion is $70 \%$. (Figure 8 ) The image elements collected from the above data are cross calculated. There are 40 valid data pictures, which are selected by workshop participants themselves. (Figure 9) At last, they are created by art and displayed in the way of collage art under modern urban life, the actual appearance of Bangkok's Chinatown area. (Figure 10)

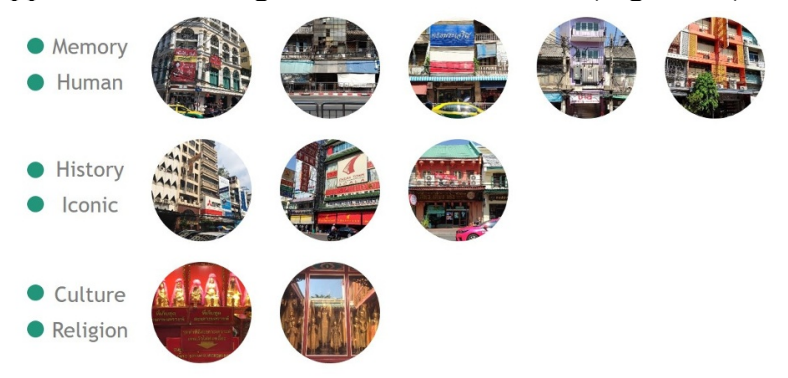

Figure 7: Data Analyses of Old Elements 


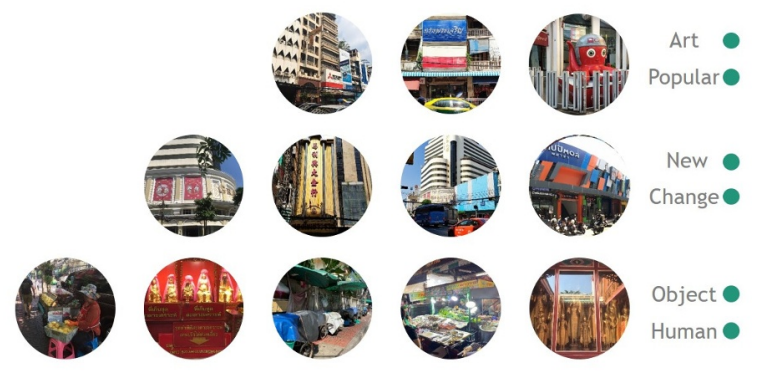

Figure 8: Data Analyses of New Elements

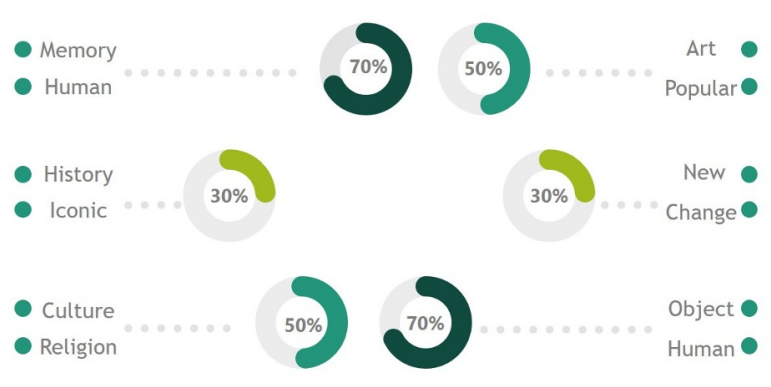

Figure 9: Data Analyses
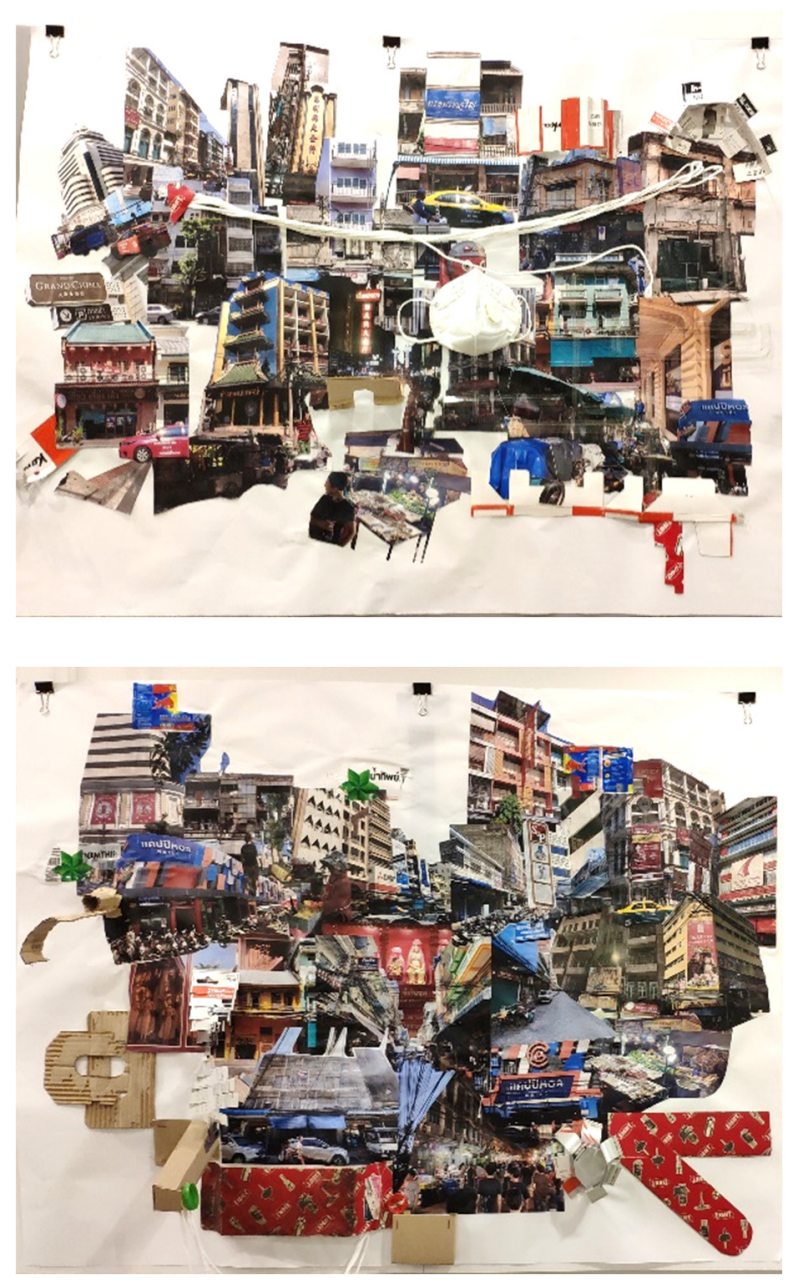

Figure 10: Collage Artworks

From the final data, we can find that among the old buildings, the number of old buildings formed by the aging of the building itself is the largest, which is also the most urgent part of the urban district to be updated, especially because some buildings are aging and abandoned due to long-term disrepair. The new buildings in urban renewal have the strongest demand for human emotion. This kind of emotion contains the nostalgic plot of the old buildings. It does not necessarily go back to a specific architectural style, but also has a series of emotional needs for the emotional building materials, human feelings of the enclosed space are defined. (Figure 11)

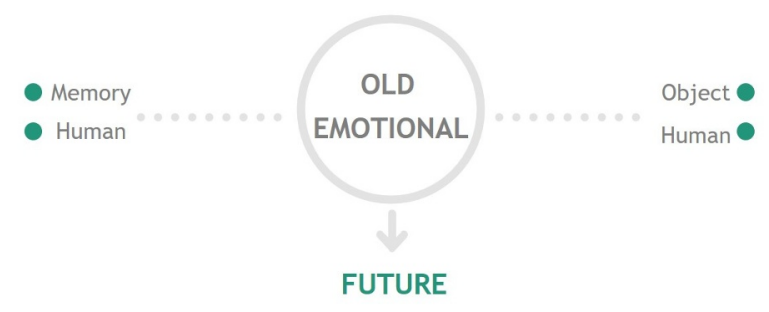

Figure 11: Finding

\section{Conclusion}

Through the way of the art workshop, the process of investigation, data collection, data classification, and art creation is adopted to explore the city districts. Using perceptual artistic creation to understand the relationship between new buildings and old buildings in urban districts, we will find that, in the construction of new buildings in urban areas, human emotional factors are the most significant determining junction, the junction between new buildings and old buildings, and the key to the paradigm shift of new building to old urban districts.

\section{REFERENCES}

1. Amjad Almusaed and Asaad Almssad. 2019. City Phenomenon between Urban Structure and Composition. In Urban Design. DOI: https://doi.org/10.5772/intechopen.90443

2. Marcelo Sagot Better. 2018. Understanding the careful urban renewal and critical reconstruction of Berlin: eco-projects of the Internationale Bauausstellung 1987. In EAUH.

3. Jeff E. Brooks-Harris and Susan R. Stock-Ward. 1999. Workshops: Designing and Facilitating Experiential Learning. SAGE Publications, Thousand Oaks.

4. Anne Marie Broudehoux. 1994. Neighborhood Regeneration in Beijing: An Overview of Projects Implemented in the Inner City Since 1990. McGill University Libraries, Montreal.

5. François Chaslin and Virginie Picon-Lefebvre. 1989. La Grande Arche de La Défense. (1989), 215.

6. Nan Ellin. 2013. Integral Urbanism. Routledge, New York.

7. Diane Ghirardo. 1996. Architecture after Modernism. Thames \& Hudson, London.

8. Hardt-Waltherr Hämer. 1990. 12 Principles of Cautious Urban Renewal. Retrieved from https://www.internationale-bauausstellungen.de

9. Susann Liepe, Marianna Poppitz, Nils Scheffler, and Ariane Sept. 2010. Wissenschaftliche Studie IBA '87 
in Berlin. Senatsverwaltung für Stadtentwicklung Berlin, Berlin.

10. Todd James Pierce. 2015. College. Oxford University Press, Oxford.

11. Colin Rowe. 1984. Collage City. The MIT Press, Cambridge.

12. Jennifer A.E. Shields. 2014. Collage and Architecture. Routledge, New York.

13. Robert Venturi. 1966. Complexity and contradiction in architecture. The Museum of Modern Art, New York.
14. Urban Waste. Urban Metabolism. Retrieved from http://www.urban-waste.eu/urban-metabolism

15. Berlin in Brief: History. Retrieved from https://www.berlin.de/berlin-imueberblick/en/history/the-fall-of-the-wall-andreunification/

16. Self-Construction Experiment Wohnregal. Retrieved from https://www.internationale-bauausstellungen.de

17. Grand Arche de la Défense. Retrieved from http://paris.dukegill.com/defense.htm 